\title{
The association between hope, marital status, depression and persistent pain in men and women following cardiac surgery
}

\author{
Ann Kristin Bjørnnes ${ }^{1,2^{*}}$ (D), Monica Parry ${ }^{2}$, Irene Lie ${ }^{3}$, Ragnhild Falk ${ }^{4}$, Marit Leegaard ${ }^{5}$ and Tone Rustøen ${ }^{1,6}$
}

\begin{abstract}
Background: Cardiac surgery is a major life event, and outcomes after surgery are associated with men's and women's ability to self-manage and cope with their cardiac condition in everyday life. Hope is suggested to impact cardiac health by having a positive effect on how adults cope with and adapt to illness and recommended lifestyle changes.

Methods: We did a secondary analysis of 416 individuals ( $23 \%$ women) undergoing elective coronary artery bypass graft and/or valve surgery between March 2012 and September 2013 enrolled in randomized controlled trial. Hope was assessed using The Herth Hope Index (HHI) at three, six and 12 months following cardiac surgery. Linear mixed model analyses were performed to explore associations after cardiac surgery between hope, marital status, depression, persistent pain, and surgical procedure.

Results: For the total sample, no statistically significant difference between global hope scores from 3 to 12 months was observed (ranging from $38.3 \pm 5.1$ at 3 months to $38.7 \pm 5.1$ at 12 months), and no differences between men and women were observed at any time points. However, 3 out of 12 individual items on the $\mathrm{HHI}$ were associated with significantly lower scores in women: \#1) I have a positive outlook toward life, \#3) I feel all alone, and \#6) I feel scared about my future. Over the study period, diminished hope was associated with older age, lower education, depression prior to surgery, and persistent pain at all measurement points. Isolated valve surgery was positively associated with hope. While neither sex nor marital status, as main effects, demonstrated significant associations with hope, women who were divorced/widowed/single were significantly more likely to have lower hope scores over the study period.
\end{abstract}

Conclusion: Addressing pain and depression, and promoting hope, particularly for women living alone may be important targets for interventions to improve outcomes following cardiac surgery.

Trial registration: Clinical Trials gov Identifier: NCT01976403. Date of registration: November 28, 2011.

Keywords: Cardiac surgery, Hope, Marital status, Persistent pain, Depression

\section{Background}

Approximately $8 \%$ of men and $5 \%$ of women in the United States (US) have coronary heart disease (CHD), and $2.5 \%$ of the US population have heart valve disease, with similar prevalence in both men and women [1].

\footnotetext{
* Correspondence: ann-kristin.bjornnes@hioa.no

The study was conducted at the Departments of Cardiothoracic Surgery, Oslo University Hospital, Oslo, Norway

${ }^{1}$ Department of Research and Development, Division of Emergencies and Critical Care, Oslo University Hospital, Ullevål, P.O Box 4956, Nydalen, 0424 Oslo, Norway

${ }^{2}$ Lawrence S. Bloomberg Faculty of Nursing, University of Toronto, 155 College Street, Suite 130, Toronto, ON M5T 1P8, Canada

Full list of author information is available at the end of the article
}

Complex surgical procedures (e.g., coronary artery bypass graft $[C A B G]$ surgery and heart valve surgery) are commonly performed to reduce cardiac mortality and to relieve associated symptoms such as cardiac pain [2]. Cardiac surgery is a major life event [3], and outcomes after surgery are associated with the individual's ability to self-manage and cope with their cardiac condition in everyday life. Following surgery, individuals are encouraged to set and achieve goals related to modification and control of physiological risk factors (e.g., weight, blood pressure, blood lipids) and promotion of healthy lifestyle routines related to nutrition, exercise and sleep [4]. Hope refers to a goal-directed cognitive process, 
including pathway thinking (i.e., the capacity to establish ways for reaching goals) and agency thinking (i.e., ability to sustain the motivation to purse goals) [5]. In that way hope might be an important factor after cardiac surgery [6].

Hope is also a positive phenomenon, and is linked to optimism [7], psychological well-being, improved physical health and positive CHD outcomes [6, 8, 9]. Dufault and Martocchio (1985) propose an often cited definition [10] that suggest hope is "a multidimensional dynamic life force characterized by a confident yet uncertain expectation of achieving a future good which, to the hoping person, is realistically possible and personally significant". Hope is future-oriented, and has a positive association with psychosocial relationships [5, 11, 12], stimulates coping, and adaptation to life changes $[5,13]$ across affective, cognitive, and behavioural dimensions $[11,14]$. Hope is described to be negatively correlated with low socioeconomic status, low education, living alone, and other chronic conditions $[15,16]$. Low levels of hope are also reported to be related to persistent pain, fatigue, lack of control, impaired cognition, unresolved grief, undesirable living arrangements and poor healthrelated quality of life (HRQL) across a wide range of conditions [16-18]. DuBois et al. [19] suggest that positive psychological constructs, such as hope, impact cardiac health by having a positive effect on how adults cope with and adapt to illness and recommended lifestyle changes. In a prospective cohort study by Feldman et al. [6] $(N=391)$, hope predicted health-promoting behaviours at one-month follow-up in immigrants undergoing cardiovascular risk screening and assessment. Similarly, Dunn et al. [12] $(N=324)$ found that individuals with $\mathrm{CHD}$ who experienced diminished hope were less likely to exercise after coronary events.

In contrast to hope, depression is associated with poorer recovery and outcomes after cardiac surgery [3, 20 ]. Approximately $4 \%$ of the general US adult population suffers from major depression [20]. The prevalence is about twice as high in women compared to men, and depression is associated with a $50 \%$ increased risk of cardiac events in women [21]. Preoperative depression is predictive of post-surgery depression and is associated with decreased cardiac symptom relief, quicker return of ischemic symptoms, more frequent rehospitalisation, poorer HRQL and increased mortality in the immediate postoperative period [20,22]. Approximately $20 \%$ of patients who had CABG surgery remained depressed beyond the immediate postoperative recovery period [23]. When merging results from 26 studies including 4023 participants, Alarcon et al. [24], found that depression had a significant negative correlation with hope (mean $p-0.52, p<0.05$ ).

Unrelieved acute pain is associated with an increased risk for persistent pain, with approximately 10 to $50 \%$ of acute pain transitioning into persistent pain $[25,26]$. In a prospective Canadian study [27] $(N=1247), 10 \%$ of respondents continued to report persistent postoperative pain up to two years following cardiac surgery. Women have a higher prevalence of clinically relevant pain and report more persistent pain of moderate to severe intensity up to two years after cardiac surgery [27-29]. Interestingly, persistent pain disorders have not been associated with lower levels of hope in the general population [30], however; the association between hope and persistent pain after cardiac surgery including differences related to sex has not been investigated. Sex differences are particularly important, since there is a persistent gap in the representation of women in cardiovascular research [31], and sex-stratified data reporting is recommended [21].

The Herth Hope Index (HHI) is a well-established measure of hope [14], designed to measure a global, time-independent sense of hope [32]. The HHI is based on the global and the specific dimensions of hope conceptualized by Dufault and Martocchio [10]. Although the HHI has been used to measure hope in different populations, the majority of studies have been related to cancer, and only one study has assessed hope in the general population [30]. Ten studies have used the HHI to assess hope in the cardiac population [7, 18, 33-40]. Combined, these ten studies included only 734 respondents and due to cross-sectional designs, small sample sizes, and variable follow-up times, the evidence is inconclusive. No study found was investigating the role of hope in individuals after isolated heart valve surgery.

\section{Aims}

The aims of this study were to: 1) describe hope in men and women after cardiac surgery, and 2) to examine the association between hope after cardiac surgery and the following factors: age, marital status, education, surgical procedure, depression, and persistent pain after cardiac surgery.

\section{Methods}

We did a secondary analysis of 416 individuals (23\% women) undergoing elective coronary artery bypass graft (CABG) and/or valve surgery between March 2012 and September 2013 enrolled in randomized controlled trial. As no between-group differences were found in the main trial the whole sample was included in the present study. Study procedures have been described in details elsewhere [41]. Briefly, eligible participants were $\geq 18$ years old, able to speak, read and understand Norwegian, scheduled to elective CABG and /or valve surgery, and were able to care for themselves postdischarge. The participants were recruited from two, separate cardiothoracic surgical units at Oslo University 
Hospital, Norway. Data collection was carried out prior to surgery, and at three, six and 12 months post-surgery. The Regional Committee for Medical Research Ethics in Eastern Norway approved the research and all participants provided written informed consent.

\section{Measures}

Hope was assessed at three, six and 12 months postsurgery, and was measured using the Norwegian version of the Herth Hope Index (HHI). The HHI is a shortened version of Herth Hope Scale [32], and contains 12 items measured on a 4-point Likert scale ranging from 1 (strongly disagree) to 4 (strongly agree). The scale gives one global score that ranges from 12 to 48 , as well as single-item scores that range from 1 to 4 with scores in the upper range indicating greater levels of hope. The HHI has been validated in a sample of 1893 Norwegian adults form the general population with an internal consistency coefficient of 0.81 (Cronbach's alpha) [42], and in the current sample, we obtained a Cronbach's alpha between 0.85 ( 3 months) and 0.86 (12 months after surgery).

Previous research has shown that marital/cohabitant status is a valid proxy for social support [43, 44], and we obtained information on marital status and living conditions from the demographic form prior to surgery. All respondents were asked to indicate if they were living alone or living with somebody (i.e., living with a spouse/partner, living with other adults, divorced, widowed or single).

Depression as a comorbid condition prior to surgery was assessed using The Self-Administered Comorbidity Questionnaire (SCQ-16) [45]. The SCQ-16, which has obtained a pre-test reliability of 0.94 [45], includes 15 common medical conditions, including depression, and one optional item. Respondents were asked to indicated if they had one of the listed medical conditions by answering yes/no or fill out the optional item.

Persistent postoperative pain is defined by the convention of the International Association for the Study of Pain as pain developing after surgery, with other causes of pain excluded and persisting for at least two to three months after surgery [46]. Persistent pain intensity was obtained using an item from the Brief Pain Inventory Short Form (BPI-SF) [47] at three, six and 12 months post-surgery. Data was captured as worst pain intensity in the last $24 \mathrm{~h}$ using a 0 (no pain) to 10 (pain as bad as you can imagine) numeric rating scale. The BPI-SF is a reliable and valid scale for assessing acute and persistent pain in individuals after cardiac surgery, and obtained a Cronbach's alpha coefficients between 0.84 and 0.94 in the Norwegian validation study [48].

\section{Analysis}

Data were were analyzed using the Stata statistical software [49]. All tests were two-tailed and associations were considered statistically significant if $p \leq 0.05$. The distribution of data was assessed graphically (i.e., histograms), depending of normality, continuous variables were compared using a Student's $t$-test or Man-Whitney $U$-test. Differences between categorical variables were assessed using cross tabulation with chi-square analyses or the Fisher's exact test.

Missing values in the HHI were replaced with the item's mean value if $20 \%$ or less of the items were missing from an individual's response. If more values were missing, the respondents were not included in the longitudinal analyses. The two negative items (i.e., 3 and 6), were reverse scored so that a higher score would indicate higher levels of hope [32].

Associations between hope (i.e., HHI) and the factors of interest were assessed by estimating a linear mixed model with a correlation structure based on the AIC (Aikaike Information Criterion) [50]. Selected covariates included time after surgery, sex, age, marital status (i.e., married/cohabitant/partner or living alone), education (i.e., primary school, and greater than primary school), surgical procedure (i.e., isolated CABG surgery, isolated valve surgery or both $C A B G$ /valve surgery), depression, and persistent pain (worst pain intensity). Marital status and depression have shown significant associations with hope in previous studies among individuals with CHD, whereas age and sex have had a significant impact on hope levels in the general population. Since no previous study has investigated hope after isolated valve surgery, surgical procedure was included as a covariate. Persistent pain intensity was considered as a time-varying factor. The final model assessed the HHI total score as a dependent factor, with time after surgery, age, sex, marital status, surgical procedure, depression and persistent pain (worst pain intensity) as independent factors. Interaction between sex and marital status was included as well. A significant interaction term would imply that the relationship between hope and marital status differed between sexes. The covariates were included as fixed factors in the model, and participants and time after surgery were considered as random factors with an unstructured covariance matrix.

We compared our results with previous studies using means, standard deviations, and sample sizes to calculate effect sizes with 95\% confidence intervals (CIs) which were represented by Cohen's $d$. Effect sizes indicate the magnitude of differences between the mean HHI global score at 12 months obtained in our study and the mean HHI global scores obtained from previous studies using the HHI in the cardiac population. Positive effect sizes would suggest that individuals in our study reported 
higher levels of hope than previous studies, whereas negative effect sizes would suggest lower levels of hope compared to previous studies. Effect sizes $<0.2$ represent a small effect, 0.5 to 0.8 suggest a medium effect, and $>0.8$ indicate a large effect size [51].

\section{Results}

Demographic and clinical characteristics.

Of the 416 participants at baseline, 349 (84\%) completed the study (Fig. 1). The mean age of the participants was $66 \pm 10$ years, and the majority was men (77\%) (Table 1). Women were in average 5 years older than men, and $27 \%(n=27)$ of women compared with $16 \%(n=46)$ of men had not completed secondary education $(p=0.015)$. Most men $(80 \%, n=241)$ were married/living with a partner, however, less than half $(46 \%, n=41)$ of the women reported to live with somebody. For women, the most common surgical procedure was isolated valve surgery $(61 \%, n=57)$, and isolated CABG surgery, involving internal mammary artery grafts with additional saphenous grafts, was the most frequent procedure among men $(51 \%, n=165)$. The median number of additional medical conditions for women was 2 (range 0-6), while the median number of comorbid ailment was 1 (range 0-6) among men. The comorbid conditions with a prevalence of $10 \%$ or more in one of the sexes are reported in Table 1. Women had a higher prevalence of depression (13\%, $n=12$ vs. $3 \% n=9, p<0.001)$ compared to men. No sex differences were observed for preoperative worst pain intensity; however, women reported significantly more intense worst pain at 3, 6 and 12 months compared to men.

\section{Hope}

The mean global HHI score ranged from $38.3 \pm 5.1$ at 3 months to $38.7 \pm 5.1$ at 12 months. The differences in global hope score and mean scores on individual items from 3 to 12 months were small and not statistically significant, and only results from 12 months are shown (Table 2). At 12 months women had significantly lower scores on the items 1,3 and 6 compared to men. According to the mixed model analysis (Table 3), age, lower education, depression, and persistent pain were inversely associated with hope for both men and women. Isolated valve surgery was positively associated with hope. For women only, marital status (i.e., divorced/ widowed/single) was associated with lower hope scores over the study period.

The mean global HHI scores reported in different studies in the cardiac population and the effect sizes represented by the Cohen's $d$ are reported in Table 4. The results indicated that the current study obtained higher scores on the HHI compared to Madhavi et al. [34] (i.e., large effect), Evangelista et al. [39] (i.e., small effect),

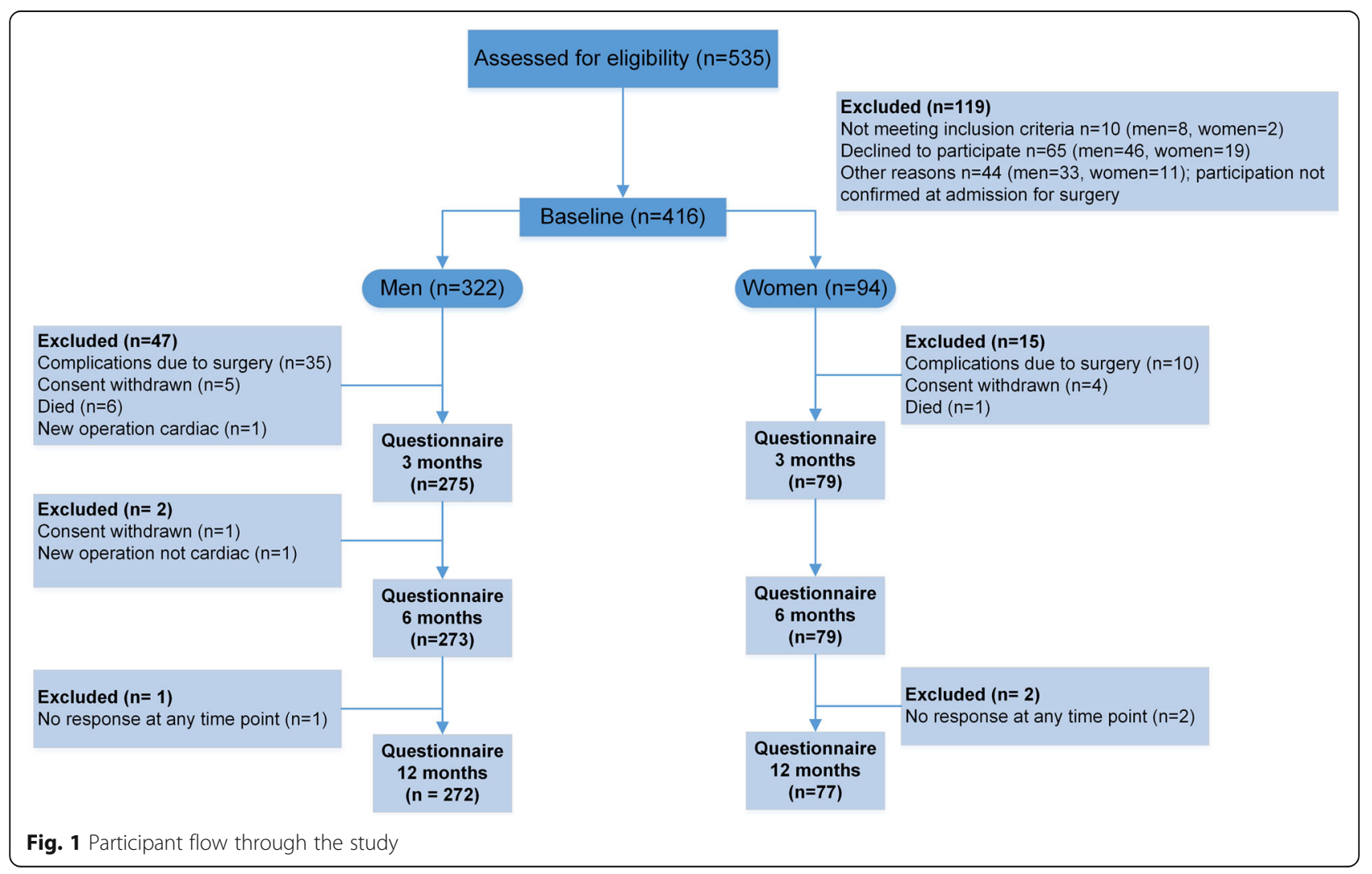


Table 1 Demographic and clinical characteristics by sex $(N=416)$

\begin{tabular}{|c|c|c|c|c|}
\hline \multicolumn{2}{|l|}{ Characteristics } & \multirow{2}{*}{$\frac{\text { Men }(n=322)}{65 \pm 10}$} & \multirow{2}{*}{$\begin{array}{l}\text { Women }(n=94) \\
70 \pm 12\end{array}$} & \multirow{2}{*}{$\frac{p \text { value }}{<0.001}$} \\
\hline Age & in years, mean $\pm S D$ & & & \\
\hline \multirow[t]{2}{*}{ Education $^{\mathrm{b}}$} & Less than high school/secondary, n (\%) & $46(16)$ & $24(27)$ & \multirow[t]{2}{*}{0.015} \\
\hline & High school/secondary or higher, n (\%) & $245(84)$ & $64(73)$ & \\
\hline \multirow[t]{2}{*}{ Marital status ${ }^{c}$} & Married/Cohabitant/Partner, n (\%) & $241(80)$ & $41(46)$ & \multirow[t]{2}{*}{$<0.001$} \\
\hline & Divorced/Widowed/Single, n (\%) & $59(20)$ & $49(54)$ & \\
\hline \multirow[t]{3}{*}{ Type of Surgery } & Isolated CABG ${ }^{\mathrm{d}}, \mathrm{n}(\%)$ & $165(51)$ & $26(28)$ & \multirow[t]{3}{*}{$<0.001$} \\
\hline & Isolated Heart Valve, n (\%) & $116(36)$ & $57(61)$ & \\
\hline & CABG and Valve, $n(\%)$ & $41(13)$ & $11(11)$ & \\
\hline \multirow[t]{4}{*}{ Worst pain intenstity } & Pre-surgery, mean $\pm S D$ & $3.0 \pm 2.3$ & $3.3 \pm 2.4$ & 0.322 \\
\hline & 3 months, mean \pm SD & $1.4 \pm 1.9$ & $1.8 \pm 2.7$ & 0.013 \\
\hline & 6 months, mean \pm SD & $1.2 \pm 1.7$ & $2.0 \pm 2.4$ & 0.031 \\
\hline & 12 months, mean $\pm S D$ & $1.0 \pm 1.9$ & $1.7 \pm 2.5$ & 0.034 \\
\hline \multirow[t]{8}{*}{ Comorbidities $^{\mathrm{e}, \mathrm{c}}$} & Hypertension, n (\%) & $144(48)$ & $45(50)$ & 0.745 \\
\hline & Back/Neck problems, n (\%) & $70(23)$ & $27(30)$ & 0.201 \\
\hline & Diabetes mellitus, n (\%) & $49(16)$ & $14(16)$ & 0.885 \\
\hline & Osteoarthritis, n (\%) & $34(11)$ & $29(32)$ & $<0.001$ \\
\hline & Headache, n (\%) & $16(6)$ & $11(12)$ & 0.025 \\
\hline & Rheumatoid arthritis, n (\%) & $12(4)$ & $11(12)$ & 0.004 \\
\hline & Depression, n (\%) & $9(3)$ & $12(13)$ & $<0.001$ \\
\hline & Other medical problems, n (\%) & $69(23)$ & $22(24)$ & 0.675 \\
\hline \multicolumn{2}{|c|}{ Number of comorbidities ${ }^{\mathrm{e}}$ median (range) } & $1(0-6)$ & $2(0-6)$ & 0.010 \\
\hline Body mass index & $\mathrm{Kg} / \mathrm{m}^{2}$, mean $\pm \mathrm{SD}$ & $27.4 \pm 3.8$ & $26.4 \pm 4.8$ & 0.046 \\
\hline
\end{tabular}

${ }^{a} p$ values obtained from students $t$-tests or Mann-Whitney U-test (continuous variables) and Pearson Chi-squared tests or Fischer's exact (dichotomous variables), ${ }^{\mathrm{b}}$ Missing $=37,{ }^{\mathrm{C}}$ Missing $=22$ for men and 4 for women, ${ }^{\mathrm{d}} \mathrm{CABG}=$ Coronary artery bypass graft, ${ }^{\mathrm{e}} \mathrm{SCQ}-16=$ The self administered comorbidity questionnaire,

$\mathrm{SD}=$ Standard dividation

Table 2 Level of hope at 12 months in individual items in the Herth Hope Index by sex $(N=320)$

\begin{tabular}{|c|c|c|c|}
\hline \multirow[t]{2}{*}{ Individual Items } & \multirow{2}{*}{$\begin{array}{l}\text { Men } \\
\text { Mean } \pm \text { SD }\end{array}$} & \multirow{2}{*}{$\begin{array}{l}\text { Women } \\
\text { Mean } \pm \text { SD }\end{array}$} & \multirow[t]{2}{*}{$p$ value } \\
\hline & & & \\
\hline 1. I have a positive oulook torward life & $3.5 \pm 0.6$ & $3.2 \pm 0.6$ & 0.003 \\
\hline 2. I have short and/or long range goals & $3.2 \pm 0.6$ & $3.1 \pm 0.8$ & 0.465 \\
\hline 3. I feel all alone ${ }^{a}$ & $3.6 \pm 0.9$ & $3.2 \pm 0.8$ & $<0.001$ \\
\hline 4. I can see possibilities in the midst of difficulties & $3.1 \pm 0.8$ & $3.2 \pm 0.7$ & 0.819 \\
\hline 5. I have a faith that gives me comfort & $2.4 \pm 1.0$ & $2.6 \pm 1.0$ & 0.051 \\
\hline 6. I feel scared about my future ${ }^{a}$ & $3.2 \pm 0.8$ & $2.8 \pm 0.9$ & 0.004 \\
\hline 7. I can recall happy/joyful times & $3.5 \pm 0.5$ & $3.5 \pm 0.6$ & 0.802 \\
\hline 8. I have a deep inner strength & $3.2 \pm 0.6$ & $3.2 \pm 0.6$ & 0.926 \\
\hline 9. I am able to give and receive caring/love & $3.4 \pm 0.5$ & $3.4 \pm 0.6$ & 0.710 \\
\hline 10. I have a sense of direction & $3.2 \pm 0.6$ & $3.1 \pm 0.6$ & 0.502 \\
\hline 11. I belive that each day has a potential & $3.3 \pm 0.6$ & $3.2 \pm 0.6$ & 0.285 \\
\hline 12. I fell my life has value and worth & $3.4 \pm 0.6$ & $3.3 \pm 0.6$ & 0.243 \\
\hline Herth Hope Index total score & $38.9 \pm 4.9$ & $38.1 \pm 5.9$ & 0.455 \\
\hline
\end{tabular}


Table 3 Linear mixed model; variables associated with the Herth Hope Index total score a across time

\begin{tabular}{|c|c|c|c|}
\hline Variables & Coef. & $95 \%$ C.I & $p$ value \\
\hline \multicolumn{4}{|l|}{ Time $^{b}$} \\
\hline 6 months & -0.11 & {$[-0.58,0.37]$} & 0.646 \\
\hline 12 months & 0.27 & {$[-0.21,0.75]$} & 0.267 \\
\hline $\operatorname{Sex}^{\mathrm{c}}$ & 0.94 & {$[-0.53,2.42]$} & 0.211 \\
\hline Age $>65^{d}$ & -0.96 & {$[-1.86,-0.05]$} & 0.039 \\
\hline \multicolumn{4}{|l|}{ Surgery } \\
\hline Isolated Valve & 1.16 & {$[0.23,2.11]$} & 0.014 \\
\hline Valve and $C A B G$ & 0.29 & {$[-1.22,1.81]$} & 0.711 \\
\hline Marital status ${ }^{f}$ & -0.79 & {$[-2.01,0.43]$} & 0.208 \\
\hline Educational status $^{9}$ & 1.21 & {$[0.09,2.31]$} & 0.033 \\
\hline Depression & -4.78 & {$[-6.71,-2.83]$} & $<0.001$ \\
\hline Worst pain intensity & -0.39 & {$[-0.54,-0.23]$} & $<0.001$ \\
\hline Sex Marital status & -2.38 & {$[-4.61,-0.12]$} & 0.039 \\
\hline
\end{tabular}

${ }^{a}$ Higher scores indicating higher levels of hope

${ }^{\mathrm{b}}$ Time after surgery, 3 months as reference

${ }^{c}$ Men $=0$, Women $=1$

${ }^{\mathrm{d}}$ Age $\leq 65=0$, Age $>65=1$

eIsolated CABG surgery as reference

${ }^{\mathrm{f}}$ Married/Cohabitant/Partner $=0$, Divorced/Widowed/Single $=1$

'Less than high school/secondary $=0$, High school/secondary or higher $=1$
Rustøen et al. [38] (i.e., small effect), and Staples et al. [40] (i.e., small effect). The current study obtained lower scores on the HHI compared to Bay et al. [36] (i.e., small effect), Beckie et al. [7] (i.e., medium effect), Eriksson et al. [35] (i.e., medium effect), McGurk et al. [33] (i.e., small effect), Kelly-Tobin [18] (i.e., small effect), and Van Kuiken et al. [37] (i.e., small effect).

\section{Discussion}

The purpose of this study was to describe hope characteristics and to identify factors that were associated with hope in men and women following cardiac surgery. For the total sample, no statistically significant difference between global hope scores from 3 to 12 months was observed, and no between sex differences were observed at any time points. However, 3 out of 12 items on the HHI were associated with lower scores in women: \#1) I have a positive outlook toward life, \#3) I feel all alone, and \#6) I feel scared about my future. Diminished hope was associated with older age, lower education, depression prior to surgery, and persistent pain (worst pain intensity) at all measurement points. Isolated valve surgery was positively associated with hope. While neither sex nor marital status, as main effects, demonstrated significant associations with hope, women who were divorced/

Table 4 Mean scores and standard deviation reported in different studies that used the Herth Hope Index and standardized effect sizes (Cohen's d)

\begin{tabular}{|c|c|c|c|}
\hline Study (year), country & Sample (N) & $\mathrm{HHI}$ global, mean \pm SD & Cohen's d [95\% Cl] \\
\hline $\begin{array}{l}\text { Present study, } \\
\text { Norway }\end{array}$ & Cardiac surgery (416) & $\begin{array}{l}3 \text { months: } 38.3 \pm 5.1 \\
6 \text { months: } 38.3 \pm 5.4 \\
12 \text { months: } 38.7 \pm 5.1\end{array}$ & $0.46[0.35,0.57]^{a}$ \\
\hline $\begin{array}{l}\text { Mahdavi (2016), [34] } \\
\text { Iran }\end{array}$ & Cardiac surgery (80) & $\begin{array}{l}\text { Pre-surgery: } 20.2 \pm 8.1 \\
1 \text { month: } 23.4 \pm 6.8\end{array}$ & $2.81[2.51,3.11]^{\mathrm{b}}$ \\
\hline $\begin{array}{l}\text { Kelly-Tobin (2016), [18] } \\
\text { USA }\end{array}$ & Women after Ml (91) & $39.06 \pm 4.65$ & $-0.32[-0.63,-0.01]^{c}$ \\
\hline $\begin{array}{l}\text { Eriksson (2013), [35] } \\
\text { Sweden }\end{array}$ & After MI (13) & $\begin{array}{l}1 \text { month: } 40.6 \pm 5.8 \\
13 \text { months: } 41.6 \pm 5.4 \\
24 \text { months: } 41.5 \pm 6.7\end{array}$ & $-0.57[-1.12,-0.01]^{b}$ \\
\hline $\begin{array}{l}\text { McGurk (2010), [33] } \\
\text { USA }\end{array}$ & Heart Failure (65) & $39.03 \pm 5.67$ & $-0.06[-0.32,0.20]^{b}$ \\
\hline $\begin{array}{l}\text { Bay (2008), [36] } \\
\text { Sweden }\end{array}$ & CABG surgery (166) & $\begin{array}{l}\text { Pre-surgery: } 40.5 \pm 5.0 \\
1 \text { month: } 40.9 \pm 5.2\end{array}$ & $-0.43[-0.67,-0.19]^{d}$ \\
\hline $\begin{array}{l}\text { Van Kuiken (2008), [37] } \\
\text { USA }\end{array}$ & Heart Failure (67) & $38.8 \pm 7.03$ & $-0.02[-0.3,0.24]^{b}$ \\
\hline $\begin{array}{l}\text { Rustøen (2005), [38] } \\
\text { Norway }\end{array}$ & Heart Failure (88) & $37.69 \pm 5.3$ & $0.2[-0.04,0.43]^{b}$ \\
\hline $\begin{array}{l}\text { Evangelista (2003), [39] } \\
\text { USA }\end{array}$ & Women, Heart Transplant Recipients (50) & $35.84 \pm 5.08$ & $0.19[-0.17,0.56]^{c}$ \\
\hline $\begin{array}{l}\text { Beckie (2001), [11] } \\
\text { USA }\end{array}$ & Women, after cardiac events (93) & $40.93 \pm 5.34$ & $-0.59[-.91,-0.28]^{\mathrm{c}}$ \\
\hline $\begin{array}{l}\text { Staples (1997), [40] } \\
\text { Canada }\end{array}$ & Cardiac surgery waiting period (21) & $38.5 \pm 4.1$ & $0.04[-0.04,0.48]^{b}$ \\
\hline
\end{tabular}

${ }^{\mathrm{a}} \mathrm{S}$ cores at 12 months compared with general Norwegian population (Rustøen et al. 2003), ${ }^{\mathrm{b}}$ Compared with values at 12 months present study, ${ }^{\mathrm{c}} \mathrm{Compared}$ with values for women at 12 months present study, ${ }^{d}$ Values at 1 month control group compared with 12 months present study, $\mathrm{Cl}=\mathrm{Confidence} \mathrm{Interval,} \mathrm{MI}=\mathrm{Myocardial}$ Infarction, CABG = Coronary Artery Bypass Graft surgery 
widowed/single were significantly more likely to have lower hope scores over the study period.

The majority of findings related to the $\mathrm{HHI}$ in the cardiac population are based on cross-sectional studies in smaller cohorts of individuals, and longitudinal studies are notably lacking. Our results add to the evidence, and at 12 months our global hope average score was lower than that for a Swedish intervention study one month after cardiac surgery [36], and compared to those reported at 13 months in a small longitudinal study by Erikson et al. [35]. Our HHI scores were substantial higher than those reported by Mahdavi et al. [34] onemonth post-cardiac surgery in an Iranian sample, and those reported 5 years after heart transplantation [39]. Our higher scores compared to those after heart transplantation [39] may be explained by the severity of the cardiac condition, although other studies assessing hope in individuals suffering from life-threatening diseases have obtained HHI scores similar to our study [42, 52], suggesting that there is no linear relationship between experiences of hope and disease severity. Socioeconomic circumstances are also reported to influence hope [15, 53], and we observed a negative association between lower education and hope. Similarly, the inferior hope outcomes in the Iranian sample [34] may also be explained by the more challenging socioeconomic context in Iran compared to Norway, including the respondent's younger age (mean $47.5 \pm 11$ ), female sex $(70 \%)$, and the high rate of unemployment (70\%).

Our HHI scores were not significantly different from those obtained from three cross-sectional studies with individuals living with heart failure (HF) [33, 37, 38]. A majority of the individuals in these studies were classified as NYHA class III or IV with ejection fraction less than 0.40, and adjustment for sex was lacking. Since no established cut-off exists for the HHI, direct comparison with these samples of individuals with more severe HF is problematic. However, previous studies have consistently found a significant positive association between hope and HRQL [18, 33, 38, 39, 42], indicating that interventions supporting hope in individuals after cardiac surgery may influence treatment goals.

Interestingly, in the general Norwegian population study women reported significantly higher levels of hope than men [30]. In contrast, women in our study reported significantly lower scores than men (Cohen's $d=-0.33$ CI: $[-0.59,-0.07])$, and the scores in men at 12 months were significantly higher than those among men in the general Norwegian population (Cohen's $d=0.70,95 \% \mathrm{CI}$ : $[0.57,0.84])$. Since we did not assess hope prior to surgery, we do not know if this difference appeared before or after surgery. Nevertheless, higher levels of hope might indicate that men were more resilient to negative circumstances during recovery since hope is considered to be a resource that helps individuals to set goals and cope with current life circumstances during an illness [12]. In an early study by Everson et al. [54], the lack of hope in men was found to be associated with accelerated CHD progression. Moreover, emotional well-being is reported to enhance recovery by activating the autonomic nervous system and hypothalamic-pituitary-adrenal axis that buffers the impact of stress on the immune and cardiovascular system [55]. It is also plausible that positive emotions and hope have an indirect effect through contributing to positive health behaviours, and social network engagements $[6,53,56]$, both associated with improved cardiac health.

In contrast to men, our results indicate that women experienced a global hope score at 12 months similar to the general Norwegian population [30] (Cohen's $d=0.01$, $95 \%$ CI:[-0.25, 0.24]). Moreover, the global HHI scores in women were significantly lower compared to Beckie et al. [7] who assessed hope in women hospitalized after a cardiac event (i.e., myocardial infarction [MI], isolated CABG surgery, percutaneous coronary interventions) and those reported by Kelly-Tobin [18] in a cross-sectional study investigating hope in 91 women after MI. Our scores were not significantly different from those reported by women five years after heart transplantation (Cohen's $d=0.19$, 95\% CI: [- 0.17, 0.56]. The lower scores among women may be related to the higher prevalence of persistent pain reported by women in our study. Women reported significantly higher mean worst pain intensity score at 3, 6 and 12 months compared to men. Moreover, all women consistently reported that they had more pain interference with daily activities than men [29], and persistent pain (worst pain intensity) was negatively associated with hope in the linear mixed model analysis. This evidence suggests hope measured by the HHI is influenced by external factors such as physical function and suffering [35].

The statistically significant lower scores in women related to the three HHI items indicates that women experience worse perceived social support and emotional well-being after surgery compared with men. Women's older age and widowhood may explain why women were more likely to have lower scores on these items compared to men. According to an exploratory factor analysis [57], item \#1 represents positivity, and items \#3 and \#6 represent measures of support loneliness. These items are interlinked with both affective and cognitive dimensions of hope [32], and lower scores may indicate less motivation or ability to cope and adapt to the self-management needs and activities that are essential for enhancing recovery after cardiac surgery. Items I fell all alone (i.e., item 3), and I feel scared about my future (i.e., item 6) indicate an absence of social support, and this is verified with the interaction between sex and marital status from our linear mixed model analysis that indicates 
women living alone have less hope compared to individuals living with a spouse. A close personal relationship is beneficial for individuals undergoing cardiac surgery [58], and living alone has been significantly associated with death or a new functional disability during the first two years after cardiac surgery [59]. Support has been reported to reduce stress-induced physical (e.g., increased sympathetic activation) and/or psychological (e.g., depression, anxiety) responses [60], associated with lower HRQL after cardiac surgery, particularly for women $[60,61]$.

The item I have a positive outlook toward life (i.e., item 1) is related to positivity [49]. In a prospective qualitative study, Olsman et al. [62] $(N=29)$ reported that transitions between hope, despair, and hopelessness were related to changes in physical condition. Kroemeke et al. [63] $(N=173)$ reported that hope of health improvement was associated with coping and protected the participants from an increase of depressive symptoms six months after MI. Our results complement this evidence, and we found a significant association between preoperative depression and dismissed hope after cardiac surgery. Depression is associated with poorer perceived social support, and men and women with lower support one month after a cardiac event had greater risk of angina, lower HRQL, and persistent depressive symptoms and worse adherence to risk factor and lifestyle modification management adherence (i.e., smoking, taking medication, attending cardiac rehabilitation, and diet) $[20,64][18,56]$. Conversely, hope helps individuals experiencing health challenges attain goals related to CHD self-management behaviours and form new and positive outlooks towards the future $[6,18]$.

The positive association between isolated valve surgery and hope is not clear. However, isolated valve surgery is considered to be a more complex and high-risk procedure than isolated CABG surgery [65]. It is associated with higher mortality risk, and it is plausible to think that after surviving the surgery these individuals may feel more optimistic and hopeful about their health outcomes. Moreover, most were isolated valve surgery versus combined valve and $C A B G$ surgery. Isolated valve surgery may be considered less chronic than $\mathrm{CHD}$, or isolated $C A B G$ and combined $C A B G$ and valve surgery. Isolated valve surgery is often indicated for bicuspid aortic valves, the most common adult congenital heart defect [66].

\section{Limitations}

In contrast to previous studies, our study contributes with a prospective, longitudinal design, larger sample size, and the results strengthen the evidence of previous research findings related to hope after cardiac surgery. However, the lack of assessment of hope prior to cardiac surgery is a limitation, although hope has been previously assessed in the general Norwegian population. The associations between hope and outcomes after cardiac surgery may also differ depending on the context of the disease and the individuals [16]. Our results indicate that social support impact hope after cardiac surgery, and diminished hope in women living alone was consistent across all our measure points. However, since we did not include a more comprehensive measurement of social support, we cannot draw a definite conclusion about the association between marital status, social support and hope. Similarly, we obtained information about depression from the SCQ-16 [45], prior to surgery. Inclusion of a separate measurement for depression is preferable, however, self-report is a valid source for information about comorbid ailment, and there is sufficient agreement between self-report data and medical record review [67]. As discussed, hope is associated with goal achievement. To better understand how hope may influence outcomes in men and women following cardiac surgery, future research should attempt to assess hope as a predictor of goal achievement related to selfmanagement behaviours to improve cardiac health. Lastly, given the characteristics of this cardiac surgery sample, it is not known to what degree the results generalise to other ethnic groups, and future research should examine how culture and ethnicity are related to hope and outcomes after cardiac surgery.

\section{Conclusion}

In our sample of cardiac surgery patients, we found that pre-operative depression and persistent postoperative pain were associated with diminished hope. The potential difficult experiences of less hope, specifically for women living alone, may result in a more challenging recovery. Addressing depression and pain, and promoting hope through goal attainment, may be important targets for interventions to improve outcomes for men and women following cardiac surgery.

\section{Abbreviations \\ AIC: Aikaike Information Criterion; BPI-SF: The Brief Pain Inventory Short Form: CABG: Coronary Artery Bypass Graft surgery; CHD: Coronary Heart Disease; $\mathrm{Cl}$ : Confidence Intervals; HF: Heart Failure; HHI: The Herth Hope Index; HRQL: Health-Related Quality of Life; MI: Myocardial Infarction; NRS: Numeric Rating Scale; NYHA: The New York Heart Association (NYHA) Functional Classification1 for Chronic Heart Failure; RCT: Randomized Controlled Trial; SCQ-16: the Self-Administered Comorbidity Questionnaire}

\section{Acknowledgments}

Not applicable

\section{Funding}

This study is based upon work supported by the South-Eastern Norway Regional Health Authority public health research grant (reference 2012030). The funding body had no role in the design of the study; collection, analysis, and interpretation of data: or writing the manuscript. 


\section{Availability of data and materials}

The dataset used and analysed during the current study are available from the corresponding author on reasonable request.

\section{Authors' contributions}

$A K B, I L, M L$ and TR formulated the research question. AKB analysed and interpreted the patient data in cooperation with RF, MP, IL and TR. AKB, MP, and TR wrote the manuscript; $A K B$ and RF wrote the analyse section, and IL, $\mathrm{ML}$ contributed with writing parts of the introduction and discussions. All authors read and approved the final manuscript.

\section{Ethics approval and consent to participate}

All procedures performed in studies involving human participants were in accordance with the ethical standards of the institutional and/or national research committee. All eligible participants received oral and written information about the study and provided written informed consent to participate. Participants were informed that they could withdraw from the study at any time during the study period without giving reasons. Ethics approval was obtained from Regional Committee for Medical Research Ethics in Eastern Norway (no. 2011/2012 A) and Social Science Data Services at Oslo University Hospital (no. 2012/16916). Clinical Trials gov Identifier: NCT0197640, registered November 28. 2011.

\section{Consent for publication}

Not applicable

\section{Competing interests}

The authors declare that they have no competing interests.

\section{Publisher's Note}

Springer Nature remains neutral with regard to jurisdictional claims in published maps and institutional affiliations.

\section{Author details}

Department of Research and Development, Division of Emergencies and Critical Care, Oslo University Hospital, Ullevål, P.O Box 4956, Nydalen, 0424 Oslo, Norway. ${ }^{2}$ Lawrence S. Bloomberg Faculty of Nursing, University of Toronto, 155 College Street, Suite 130, Toronto, ON M5T 1P8, Canada. ${ }^{3}$ Center for patient centered heart- and lung research, Department of Cardiothoracic Surgery, Division of Cardiovascular and Pulmonary Diseases, Oslo University Hospital, Ullevål, P.O Box 4956, Nydalen, 0424 Oslo, Norway. ${ }^{4}$ Oslo Centre for Biostatistics and Epidemiology, Research Support Services, Oslo University Hospital, Ullevål, P.O Box 4956, Nydalen, 0424 Oslo, Norway. ${ }^{5}$ Faculty of Health Sciences, Institute of Nursing, Oslo and Akershus University College of Applied Sciences, P.O Box 4, St. Olavs Plass, N-0130 Oslo, Norway. ${ }^{6}$ Institute of Health and Society, Oslo University Hospital, Ullevål, P.O Box 4956, Nydalen, 0424 Oslo, Norway.

Received: 26 April 2017 Accepted: 19 December 2017

Published online: 02 January 2018

\section{References}

1. Benjamin EJ, Blaha MJ, Chiuve SE, Cushman M, Das SR, Deo R, de Ferranti SD, Floyd J, Fornage M, Gillespie C, et al. Heart disease and stroke statistics - 2017 update: a report from the American Heart Association. Circulation. 2017;135(10):e146-603. doi: 10.1161/CIR.0000000000000485.

2. Szelkowski LA, Puri NK, Singh R, Massimiano PS. Current trends in preoperative, intraoperative, and postoperative care of the adult cardiac surgery patient. Curr Probl Surg. 2015;52(1):531-69. doi: 10.1067/j.cpsurg. 2014.10.001

3. Lie I, Bunch EH, Smeby NA, Arnesen H, Hamilton G. Patients' experiences with symptoms and needs in the early rehabilitation phase after coronary artery bypass grafting. J Cardiovasc Nurs. 2012;11(1):14-24. doi: 10.1016/j. ejcnurse.2010.09.004

4. Jaarsma T, Årestedt KF, Mårtensson J, Dracup K, Strömberg A. The European heart failure self-care behaviour scale revised into a nine-item scale (EHFSCB-9): a reliable and valid international instrument. Eur J Heart Fail. 2009;11(1):99-105. doi: 10.1093/eurjhf/hfn007.

5. Snyder CR. Hope theory: rainbows in the mind. Psychol Inq. 2002;13(4):24975. doi: 10.1207/S15327965PLI1304_01.
6. Feldman DB, Sills JR. Hope and cardiovascular health-promoting behaviour: education alone is not enough. Psychol Health. 2013;28(7):727-45. doi: 10. 1080/08870446.2012.754025.

7. Beckie TM, Beckstead JW, Webb MS. Modeling women's quality of life after cardiac events. West J Nurs Res. 2001;23(2):179-94. doi: 10.1177/ 019394590102300206

8. Boehm JK, Peterson C, Kivimaki M, Kubzansky LD. Heart health when life is satisfying: evidence from the Whitehall II cohort study. Eur Heart J. 2011; 32(21):2672-7. doi: 10.1093/eurheartj/ehr203.

9. Kim ES, Hagan KA, Grodstein F, DeMeo DL, De Vivo I, Kubzansky LD. Optimism and cause-specific mortality: a prospective cohort study. Am J Epidemiol. 2016;185(1):21-9. doi: 10.1093/aje/kww182.

10. Dufault K, Martocchio BC. Symposium on compassionate care and the dying experience. Hope: its spheres and dimensions. Nurs Clin North Am. 1985;20(2):379-91.

11. Schaufel MA, Nordrehaug JE, Malterud K. Hope in action-facing cardiac death: a qualitative study of patients with life-threatening disease. Int J Qual Stud Health Well-being. 2011;6(1) 10.3402/qhw.v6i1.5917.

12. Dunn SL, Dunn LM, Rieth NP, Olamijulo GB, Swieringa LL, Holden TP, Clark JA, DeVon HA, Tintle NL. Impact of home-and hospital-based exercise in cardiac rehabilitation on hopelessness in patients with coronary heart disease. J Cardiopulm Rehabil Prev. 2017;37(1):39-48. doi: 10.1097/HCR. 0000000000000205

13. Kornadt AE, Voss P, Rothermund K. Hope for the best, prepare for the worst? Future self-views and preparation for age-related changes. Psychol Aging. 2015;30(4):967. doi: 10.1037/pag0000048.

14. Dunn SL. Identifying and promoting hope in patients. West J Nurs Res. 2016:38(3):267-9. doi: 10.1177/0193945915614932.

15. Fitzgerald Miller J. Hope: a construct central to nursing. Nurs Forum. 2007; 4291:12-9. doi: 10.1111/j.1744-6198.2007.00061.x

16. Schiavon CC, Marchetti E, Gurgel LG, Busnello FM, Reppold CT. Optimism and hope in chronic disease: a systematic review. Front Psychol. 2016;7: 2022. doi: 10.3389/fpsyg.2016.02022.

17. Tutton $\mathrm{E}$, Seers $\mathrm{K}$, Langstaff D. An exploration of hope as a concept for nursing. J Orthop Nurs. 2009;13(3):119-27. doi: 10.1016/j.joon.2009.07.006.

18. Kelly-Tobin, Alice Mary: Hope and Health Related Quality of Life of Older Women Who Have Had Heart Attacks. 2016; CUNY Academic Works. Url: https://academicworks.cuny.edu/gc etds/1252/. Accessed 14 Feb 2017.

19. DuBois CM, Lopez OV, Beale EE, Healy BC, Boehm JK, Huffman JC. Relationships between positive psychological constructs and health outcomes in patients with cardiovascular disease: a systematic review. Int J Cardiol. 2015;195:265-80. doi: 10.1016/j.ijcard.2015.05.121.

20. Lichtman JH, Froelicher ES, Blumenthal JA, Carney RM, Doering LV, FrasureSmith N, Freedland KE, Jaffe AS, Leifheit-Limson EC, Sheps DS. Depression as a risk factor for poor prognosis among patients with acute coronary syndrome: systematic review and recommendations a scientific statement from the American Heart Association. Circulation. 2014:129(12):1350-69. doi: 10.1161/Cir.0000000000000019.

21. Mehta LS, Beckie TM, DeVon HA, Grines CL, Krumholz HM, Johnson MN, Lindley KJ, Vaccarino V, Wang TY, Watson KE. Acute myocardial infarction in women. Circulation. 2016;133(9):916-47. doi: 10.1161/CIR.0000000000000351.

22. Tully PJ, Baumeister H, Bennetts JS, Rice GD, Baker RA. Depression screening after cardiac surgery: a six month longitudinal follow up for cardiac events, hospital readmissions, quality of life and mental health. Int J Cardiol. 2016; 206:44-50. doi: 10.1016/j.ijcard.2016.01.015.

23. Ravven SMD, Bader CBA, Azar AP, Rudolph JLMDSM. Depressive symptoms after CABG surgery: a meta-analysis. Harv Rev Psychiatry. 2013;21(2):59-69. doi: 10.1097/HRP.0b013e31828a3612.

24. Alarcon GM, Bowling NA, Khazon S. Great expectations: a meta-analytic examination of optimism and hope. Pers Individ Dif. 2013;54(7):821-7. doi: 10.1016/j.paid.2012.12.004

25. Sessle BJ. The pain crisis: what it is and what can be done. Pain Res Treat. 2012;2012:6. doi: 10.1155/2012/703947.

26. Meissner W, Coluzzi F, Fletcher D, Huygen F, Morlion B, Neugebauer E, Pérez AM, Pergolizzi J. Improving the management of post-operative acute pain: priorities for change. Curr Med Res Opin. 2015:1-13. doi: 10.1185/03007995.2015.1092122.

27. Choiniere M, Watt-Watson J, Victor JC, Baskett RJ, Bussieres JS, Carrier M, Cogan J, Costello J, Feindel C, Guertin MC, et al. Prevalence of and risk factors for persistent postoperative nonanginal pain after cardiac surgery: a 2-year prospective multicentre study. CMAJ. 2014;186(7):E213-23. doi: 10. 1503/cmaj.131012. 
28. Katz J, Weinrib A, Fashler SR, Katznelzon R, Shah BR, Ladak SS, Jiang J, Li Q, McMillan K, Mina DS, et al. The Toronto general hospital transitional pain service: development and implementation of a multidisciplinary program to prevent chronic postsurgical pain. J Pain Res. 2015;8:695-702. doi: 10.2147/ JPR.S91924.

29. Bjornnes AK, Parry M, Lie I, Fagerland MW, Watt-Watson J, Rustoen T, Stubhaug A, Leegaard M. Pain experiences of men and women after cardiac surgery. J Clin Nurs. 2016;25(19-20):3058-68. doi: 10.1111/jocn.13329.

30. Rustøen T, Wahl AK, Hanestad BR, Lerdal A, Miaskowski C, Moum T. Hope in the general Norwegian population, measured using the Herth hope index. Palliat Support Care. 2003;1(4):309-18.

31. Hayes SN, Wood SF, Mieres JH, Campbell SM, Wenger NK. Taking a giant step toward women's heart health: finding policy solutions to unanswered research questions. Womens Health Issues. 2015;25(5):429-32. doi: 10.1016/j. whi.2015.07.001.

32. Herth K. Abbreviated instrument to measure hope: development and psychometric evaluation. J Adv Nurs. 1992;17(10):1251-9.

33. McGurk K and Roth PA. Quality of life, hope, social support, and self -care in heart failure patients. Thesis, University of San Diego. 2010. p. 176. ProQuest Dissertations Publishing, viewed April 17, 2017.

34. Mahdavi A, Esmaeili R, Heidari-Gorji MA, Mohammadi-Tazeh F, Cherati JY. Anxiety and hope to life in open heart surgery patients-a cross sectional study. J Cardiovasc Dis Res. 2016;7(1):23. doi: 10.5530/jcdr.2016.1.3.

35. Eriksson M, Asplund K, Hochwalder J, Svedlund M. Changes in hope and health-related quality of life in couples following acute myocardial infarction: a quantitative longitudinal study. Scand J Caring Sci. 2013;27(2): 295-302. doi: 10.1111/j.1471-6712.2012.01032.x

36. Bay PS, Beckman D, Trippi J, Gunderman R, Terry C. The effect of pastoral care services on anxiety, depression, hope, religious coping, and religious problem solving styles: a randomized controlled study. J Relig Health. 2008; 47(1):57-69. doi: 10.1007/s10943-007-9131-4

37. Van Kuiken DM. The Role of Hope in Self-care in Persons with Heart Failure. Thesis. University of Cincinnati. 2008. p. 153. ProQuest Dissertations Publishing, viewed April 17, 2017

38. Rustøen T, Howie J, Eidsmo I, Moum T. Hope in patients hospitalized with heart failure. Am J Crit Care. 2005:14(5):417-25.

39. Evangelista LS, Doering LV, Dracup K, Vassilakis ME, Kobashigawa J. Hope, mood states and quality of life in female heart transplant recipients. J Heart Lung Transplant. 2003;22(6):681-6. doi: 10.1016/S1053-2498(02)00652-6.

40. Staples P, Jeffrey J. Quality of life, hope, and uncertainty of cardiac patients and their spouses before coronary artery bypass surgery. Can J Cardiovasc Nurs. 1997;8(1):7-16.

41. Bjornnes AK, Parry M, Lie I, Fagerland MW, Watt-Watson J, Rustoen T, Stubhaug A, Leegaard M. The impact of an educational pain management booklet intervention on postoperative pain control after cardiac surgery. Eur J Cardiovasc Nurs. 2016;16(1):18-27. doi: 10.1177/1474515116631680.

42. Wahl AK, Rustoen T, Lerdal A, Hanestad BR, Knudsen O Jr, Moum T. The Norwegian version of the Herth hope index (HHI-N): a psychometric study. Palliat Support Care. 2004;2(3):255-63.

43. Idler EL, Boulifard DA, Contrada RJ. Mending broken hearts marriage and survival following cardiac surgery. J Health Soc Behav. 2012;53(1):33-49. doi: 10.1177/0022146511432342.

44. Holt-Lunstad J, Smith TB, Layton JB. Social relationships and mortality risk: a meta-analytic review. PLoS Med. 2010;7(7):e1000316. doi: 10.1371/journal. pmed. 1000316 .

45. Sangha O, Stucki G, Liang MH, Fossel AH, Katz JN. The self-administered Comorbidity questionnaire: a new method to assess comorbidity for clinical and health services research. Arthritis Rheum. 2003;49(2):156-63. doi: 10. 1002/art.10993.

46. Merskey H, Bogduk N. International Association for the Study of Pain task force on T: classification of chronic pain : descriptions of chronic pain syndromes and definitions of pain terms. 2nd ed. Seattle: IASP Press; 1994

47. Cleeland CS, Ryan KM. Pain assessment: global use of the brief pain inventory. Ann Acad Med Singap. 1994;23(2):129-38.

48. Gjeilo KH, Stenseth R, Wahba A, Lydersen S, Klepstad P. Validation of the brief pain inventory in patients six months after cardiac surgery. J Pain Symptom Manag. 2007;34(6):648-56. doi: 10.1016/j.jpainsymman.2007.01.010.

49. StataCorp 2013. Stata statistical software: release 13. College Station, Texas: StataCorp LP.

50. Fitzmaurice GM, Laird NM, Ware JH. Applied longitudinal analysis, 2nd ed. Chichester: Wiley; 2011
51. Sullivan GM, Feinn R. Using effect size —or why the P value is not enough. J Grad Med Educ. 2012:4(3):279-82. doi: 10.4300/JGME-D-12-00156.1.

52. Utne I, Miaskowski C, Bjordal K, Paul SM, Rustoen T. The relationships between mood disturbances and pain, hope, and quality of life in hospitalized cancer patients with pain on regularly scheduled opioid analgesic. J Palliat Med. 2010; 13(3):311-8. doi: 10.1089/jpm.2009.0294.

53. Reichard RJ, Avey JB, Lopez S, Dollwet M. Having the will and finding the way: a review and meta-analysis of hope at work. J Posit Psychol. 2013;8(4): 292-304. doi: 10.1080/17439760.2013.800903.

54. Everson SA, Kaplan GA, Goldberg DE, Salonen R, Salonen JT. Hopelessness and 4-year progression of carotid atherosclerosis. Arterioscler Thromb Vasc Biol. 1997;17(8):1490-5

55. Lamers SM, Bolier L, Westerhof GJ, Smit F, Bohlmeijer ET. The impact of emotional well-being on long-term recovery and survival in physical illness: a meta-analysis. J Behav Med. 2012:35(5):538-47. doi: 10.1007/s10865-011-9379-8.

56. Bolier L, Haverman M, Westerhof GJ, Riper H, Smit F, Bohlmeijer E. Positive psychology interventions: a meta-analysis of randomized controlled studies. BMC Public Health. 2013;13(1):119. doi: 10.1186/1471-2458-13-119.

57. Higginson IJ, Donaldson N. Relationship between three palliative care outcome scales. Health Qual Life Outcomes. 2004;2(1):68. doi: 10.1186/1477-7525-2-68.

58. Feeney BC, Collins NL. A new look at social support: a theoretical perspective on thriving through relationships. Personal Soc Psychol Rev. 2015;19(2):113-47. doi: 10.1177/1088868314544222.

59. Neuman MD. WernerRM: marital status and postoperative functional recovery. JAMA Surg. 2016;151(2):194-6. doi: 10.1001/jamasurg.2015.3240.

60. Staniute M, Brozaitiene J, Bunevicius R. Effects of social support and stressful life events on health-related quality of life in coronary artery disease patients. J Cardiovasc Nurs. 2013;28(1):83-9. doi: 10.1097/JCN. ob013e318233e69d

61. Oterhals K, Hanssen TA, Haaverstad R, Nordrehaug JE, Eide GE, Norekval TM Factors associated with poor self-reported health status after aortic valve replacement with or without concomitant bypass surgery. Eur J Cardiothorac Surg. 2015:48(2):283-92. doi: 10.1093/ejcts/ezu425.

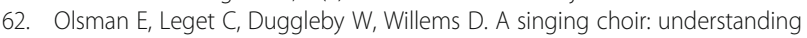
the dynamics of hope, hopelessness, and despair in palliative care patients. A longitudinal qualitative study. Palliat Support Care. 2015;13(6):1643-50. doi: 10.1017/S147895151500019X

63. Kroemeke A. Dynamics of depression symptoms after myocardial infarction - the importance of changes in hope. Psychiatr Pol. 2013;47(5):799-810.

64. Leifheit-Limson EC, KasI SV, Lin H, Buchanan DM, Peterson PN, Spertus JA, Lichtman JH. Adherence to risk factor management instructions after acute myocardial infarction: the role of emotional support and depressive symptoms. Ann Behav Med. 2012;43(2):198-207. doi: 10.1007/s12160-011-9311-z.

65. Ch'ng SL, Cochrane AD, Wolfe R, Reid C, Smith Cl, Smith JA. Procedurespecific cardiac surgeon volume associated with patient outcome following valve surgery, but not isolated CABG surgery. Heart Lung Circ. 2015;24(6): 583-9. doi: 10.1016/j.hlc.2014.11.014.

66. Coffey S, Cairns BJ, lung B. The modern epidemiology of heart valve disease. Heart. 2015;102(1):75-85. doi: 10.1136/heartjnl-2014-307020.

67. De-loyde KJ, Harrison JD, Durcinoska I, Shepherd HL, Solomon MJ, Young JM. Which information source is best? Concordance between patient report, clinician report and medical records of patient co-morbidity and adjuvant therapy health information. J Eval Clin Pract. 2015;21:339-46. doi: 10.1111/jep.12327.

\section{Submit your next manuscript to BioMed Central and we will help you at every step:}

- We accept pre-submission inquiries

- Our selector tool helps you to find the most relevant journal

- We provide round the clock customer support

- Convenient online submission

- Thorough peer review

- Inclusion in PubMed and all major indexing services

- Maximum visibility for your research

Submit your manuscript at www.biomedcentral.com/submit 